\title{
THE INTERNET AND POLITICAL PARTICIPATION OF INDONESIAN STUDENTS IN TAIWAN
}

\author{
Albertus Magnus Prestianta S.I.Kom, M.A. \\ Fakultas Ilmu Komunikasi \\ Universitas Multimedia Nusantara \\ albertus.prestianta@umn.ac.id
}

\begin{abstract}
This study examined how Internet through online news media is used to influence political participation and political efficacy. Scholars believe that the existence of Internet could have a significant impact on broadening political participation and political efficacy. This research is written based on the quantitative approach. Questionnaire items were employed to find out the relationships between online news media, political participation and political efficacy. The samples used in this research are Indonesian students in Taiwan. As predicted, the findings indicated that Internet usage, particularly online news media, was positively associated with higher levels of political participation and also political efficacy among Indonesian students in Taiwan.
\end{abstract}

Keywords: Indonesian, the Internet, online news media, political efficacy, political participation.

\section{Introduction}

After more than three decades of rule by President Soeharto, his fall in 1998 inevitably unleashed a series of political and social transformation in Indonesia. This democratic transition involved a series of liberalizing constitutional amendments and legislative reforms, which fundamentally altered the political process and structure of state institutions. Within a short period of time, Indonesians have successfully participated in three peaceful national elections in 1999, 2004 and 2009.
Although the Indonesian democratization process has been progressing steadily, the quality of Indonesian democracy and civil political participation are still under serious consideration. The level of civil political participation, particularly voters, was decline respectively. According to Minister of Home Affairs Indonesia Gamawan Fauzi, "Voters political participation in Indonesia fell constantly." Moreover Gamawan mentioned the percentage of voters participation for presidential election decreased. In 1999, 
2004 and 2009 the number of voter participation dropped respectively from 92.74 percent, 84.07 percent and 71 percent.

In Taiwan, the number of voters (Indonesian citizen) for presidential election in 2009 was less than 20 percent. Based on the records of State Election Committee of Indonesia for Taipei, the number of Indonesian citizens in Taiwan reached more than 238,000 people in 2009, consisting of Indonesian workers in the formal and informal sectors as well as students. According to Rangga Aditya Elias, Chairman of State Election Committee of Indonesia for Taipei, Taiwan turnout in second only to Malaysia.

Soebagio, H (2008) stated that political participation in democratic state is an indicator of valid implementation of highest state power exercise by people, which is embodied by their involvement in democracy event (national elections). The increasingly higher level of political participation indicates that people follow, understand, and engage in national activities. Reversely, a low level of political participation generally indicates that people place less appreciation or interest in national affairs or activities.

Political participation has been a concern of many countries around the world. With the rise of the Internet in the mid-1990s, its potential role for opening up the process of political participation to a wider and more diverse range of citizens has drawn much speculation. The Internet could have a significant impact on broadening political participation by lowering the cost of involvement, creating new mechanisms of organizing groups and opening up new channels of information that bypass traditional media gatekeepers.

Simultaneously, the existence of online news media can help to reduce communication cost, but on the other side increase information access and create new opportunities for more participation. By the lack of information exposure from television and newspaper, Indonesian people who live in Taiwan more likely use online media in order to get information. Thus, the use of online media remains high.

A majority of studies have shown positive effects of Internet use on political participation, for example, showed that the use of online news was significantly associated with voting in the 2000 United State (U.S) presidential elections. By examining data from the 2000 National Annenberg Election Survey, Kenski and Stroud (2006) found significant associations within the use of online media news in order to increase political knowledge, efficacy and participation. Di Gennaro and Dutton's (2006) study also proved that the Internet in United Kingdom gave a significant impact on political interest, efficacy and online participation.

This study will seek answer to the following question: what potential does the Internet possess for the political participation of migrants? Does the use of online news media influence individual preferences? How the communication technologies relate to individuals' exposure to diverse viewpoints and participatory activities? This question has been 
disregarded for Indonesian people who migration to Taiwan for study.

The type of participation that the writer focus on in this research relates directly to engaging in electoral process activities leading up to, but not including voting, the ultimate act of political participation. The activities leading up to voting, including persuading, discussing, campaign volunteering, contributing are as important in bringing the more disadvantaged and newer participants into the democratic process.

This research is written based on quantitative approach. Survey method will be used to map out the relationships between online media and political participation. The samples in this research are Indonesian students in Taiwan.

The selection of Indonesia students is inspired by the early research report done by Suryanef (2011) on students' perception toward political situation. Moreover he mentioned that the role of students in politic is important. The involvement of students in every phase of political life helps to form the political system. In other word, students are seen as agents of change, noblesse oblige, the future generation, or as a prophetic minority.

The goal of this study is to document the role of Internet toward the promotion of democratically desirable attitudes and behaviors when individuals use online media to keep up with news about political issues. Hopefully this study will be able to give a closer description and analysis on how Indonesian students in Taiwan perform its political participation.

\section{The role of Media}

The mass media today are omnipresent and omnipotent, if not omniscient. Media plays a significant role in the society nowadays. Media are everywhere - in the form of television, radio, newspapers, magazines and the Internet. No longer restricted to traditional means of delivery they are now accessible anywhere, at any time, through portable computers and even cellular phones. They are so much a part of modern life that their presence and influence are not always noticeable.

Today, media is considered as the fourth pillar of the state. It plays an important role as an informative bridge between governing bodies and general public. In many ways the news media also set the terms for national debates on important current events and developments. In the process they shape public perceptions of issues across the socio-economic and political continuum. By determining who has a voice in these debates and who is silenced, which issues are discussed and how they are framed, media have the potential to maintain the status quo or challenge the dominant order.

Moreover media are invariably related in some way to the prevailing structure of political and economic power (McQuail, 2010). McQuail stated that media are subject to political, economic and legal regulation. Therefore, media become effective instruments of power, with the potential capacity to exert influence in various ways.

More over McQuail (2010) believed, that media are tools to attracting and direct- 
ing public attention, persuading in matters on opinion and belief, influencing behavior, providing definitions of reality, conferring status and legitimacy and informing quickly and extensively.

The Internet has also created various kinds of virtual space. The existence of the Internet has made a possibility for messages sent to materialize at distant points. People no longer have to wait for news or wait to send it, from whatever place. There is increasingly no time restriction on when people can receive what they want to receive (McQuail, 2010).

The Internet has no doubt transformed the way in which elections are reported in many parts of the world. More recently mobile telephony, increasingly accessible to large numbers of people in developing countries (including the poor and the illiterate), has also been emerging as a news medium. Text messages are already being used to disseminate news and for political campaigning.

\section{Online News Media and Political Participation}

In less than two decades, the Internet has increasingly become a common venue for political participation. Rosenstone and Hansen (1993) stated that political participation is important because levels of engagement in a democratic system have consequences on the system's equity.

One of characteristic of political participation is attended a political rally or demonstration. These kinds of activities, which is categorize in offline political participation, is difficult to hold by Indonesian citizens who live in other country such Taiwan. Thus, online political participation can be the only answer to celebrate the democratization.

Adams (2009) argued that the development of communication technology reduce the time necessary to transmit a message over distance. The Internet is also quick and up to date and that it can provide a lot of information that necessary for civic life and public discussion. This new medium, as an interactive medium, has power to strengthen the working of direct democracy and improve relations between citizens, politicians and their intermediaries.

The diffusion and integration of digital media in social and political life are said to be creating new forms of political organization and new opportunities for political participation (Jensen \& Anduiza, 2012). Optimists believe that the abundance of political information available online may boost political interest, enhance voters' political knowledge, and increase political participation (Bonchek, 1997; Negroponte, 1995; Rash, 1997; Toffler \& Toffler, 1995). Rice (2002) strongly argues that the Internet may very well foster political involvement. Dahlgren (2009) argued, "What takes place on the net can impact profoundly on mass media coverage of party politics ( $p$. 161)."

Independent news portals also played an important role in the dissemination of political information. The online news portal KOMPAS.com, for example, provide voters with independent and reliable election information and created one of the few public 
forum to discuss politics without any restrictions.

Worth to be understood, in the Internet people can find a broad array of democratic efforts to effect social and political change (Dahlgren, 2009; Roversi, 2008). Same argument comes from Rheingold (1993). He believes political debate available online can increase peoples will to get involved in the democratic process and Rash (1997) also states that the Internet existence will open up the opportunity for new parties and ideas to develop.

A majority of studies, however, have shown positive effects of Internet use on political participation (Di Gennaro \& Dutton, 2006). Tolbert and McNeal (2003), for example, showed that the use of online news was significantly associated with voting in the 1996 and 2000 U.S. presidential elections. Examining data from the 2000 National Annenberg Election Survey, Kenski and Stroud (2006) found small but significant associations between Internet use and political knowledge, efficacy, and participation. Di Gennaro and Dutton's (2006) study of Internet data in the United Kingdom also found that online use had a significant impact on political interest, efficacy, and online participation. Based on the idea above, Internet facilitates political information access, which can motivate political participation.

However, some scholars believe that the existence of the Internet will depoliticize voters because news audiences become fragmented and the Internet offers many distrac- tions (Davis, 1999; Galston, 2003; Sunstein, 2001). From the other perspective, well-educated young adults are increasing to disengage from politics. This cohort of "critical citizens" (Norris, 1999a, as cited from Jensen \& Anduiza, 2012) tends to have lower levels of political efficacy and confidence in political institutions and authorities. But however, Bakker \& de Vreese (2011) suggest that younger adults may be more attracted to participating online rather that offline participation.

Most studies that have tested the relationship between the Internet usage and political participation have been conducted in societies with free media systems and do not take into account the unique of Indonesian political situation found in Taiwan. In Taiwan, Indonesian citizens can only rely on the Internet, particularly online news media, than traditional media like newspaper or television. Indonesian students mostly use online news media as the main source to get information regarding political issues that happened in Indonesia.

Based on the substantial support found for the hypothesis that Internet usage can increase political participation, the writer propose that online news media usage will exhibit higher level of political participation of Indonesian students in Taiwan. This process should be enhanced by the fact that Indonesian students in Taiwan use Internet as the main resource to get information related with political issues. Thus, Indonesian students accessing political information online should be more engaged and politically active than those who are not. 


\section{Online News Media and Political Efficacy}

The use of political online news media should also influence other dimensions of political participation, such as political efficacy, discussions of politics with friends and relatives, and general interest in the election. Kenski and Stroud (2006), for example found that Internet access and exposure to online information about the 2004 U.S. presidential campaign were significantly associated with political efficacy, knowledge, and participation. Other studies showed a positive link between exposure to interactive online information and political efficacy (Tedesco, 2006, 2007). A link between online usage and political discussions with friends and relatives also has been supported in various studies. Nisbet and Scheufele (2004), for example, found an interaction effect between online campaign exposure and interpersonal communication. Similarly, Valkenburg and Peter (2007) found that online communication positively affected time spent with friends.

Political efficacy is a determinant of political behavior - without feelings of competency and beliefs that one's actions are consequential, one has little incentive to participate in politics (Abramson \& Aldrich, 1982). Political participation is important because levels of engagement in a democratic system have consequences on the system's equity (Rosenstone \& Hansen, 1993). In The Voter Decides, Campbell, Gurin, and Miller (1954) described the concept of political efficacy as "the feeling that political and social change is possible, and that the individual citizen can play a part in bringing about this change" ( $p$. 187).

Despite the fact that there are no empirical studies in Indonesia that have tasted the effects of consuming online political information toward political participation for Indonesian citizen living outside the country, it is reasonable to assume that such a relationship and effect exists in a nation with so many Internet users such as Taiwan which have a well-developed Internet infrastructure. Thus, Indonesian students as users of online news media in Taiwan should have stronger feelings of political empowerment, more political discussion, and higher levels of interest in politics compared to those who are not use online media. Therefore I propose that online news media usage will exhibit higher level of political efficacy of Indonesian students in Taiwan.

With the assumption provided above I assume that online political participation positively related with political efficacy. Thus, I argued that online political participation will exhibit higher level of political efficacy.

\section{Method}

It is assumed that the Indonesian students in Taiwan constitute the most appropriate sample group in researching the effects of the Internet on political participation. Indonesian students in the university both undergraduates and postgraduates, in general, tend to follow and use the newest technologies, and they have access to technology relatively easy in Taiwan because of great Internet infrastruc- 
ture. On the one hand, they are much better educated and also tend to be more politically active than the other members of Indonesian society in Taiwan.

This research used a structured questionnaire and distributed by online survey. The questioners have already spread to Indonesian students who live in Taiwan. The questionnaire distributed by sending email through each representative in every university in Taiwan. This research acquires at least 200 respondents from more than 2,000 Indonesian students who study and live in Taiwan. The questionnaires disseminated from March 28, 2014 until April 16, 2014. Through that period of time, 206 responses were successfully collected and could be used for further analysis.

The empirical analysis is built on a comprehensive online survey, which contains two parts. The first part of the survey aims to reveal demographic features of the participants. The questionnaires asked the respondents to answer question related to (1) age, (2) gender, (3) education, (4) Internet time spend, (5) Online news time spend.

The second part contains items determining how the Internet is used and the level of their political participation and political efficacy. In this section, I divided the question into two major variables, dependent variable (online political participation and political participation) and independent variable (online news media usage). All of these items, measured with Likert scale (ranging from: $1=$ Strongly Disagree; 2 = Disagree; $3=$ Neither Agree nor Disagree; $4=$ Agree; $5=$ Strongly
Agree) which was developed using the existing empirical studies. All of these 24 items were adapted from previous empirical studies (i.g. Gibson, Lusoli and Ward 2005, Willnat, Wong, Tamam and Annette 2013, Bromley, Curtice and Seyd, 2004).

The types of online political participation, which is dependent variable, were measured with 19 items: (1) I am generally interested in what is going on in politics; (2) I am looking for political information on the web; (3) I am visiting the website of a party or political organization; (4) I am discussing politics in a chat group; (5) I am sending a political newspaper article to a friend or colleague; (6) I am signing an online petition; (7) I am participating in an online question and answer session with a politician; (8) I am sending an e-mail to a politician or government official; (9) I am donating funds online to a political cause; (10) I am signing up online as a volunteer to help with a political cause; (11) I am joining a political organization online as a member; (12) I am campaigning for the candidate of your choice; (13) I often discuss about 2014 election with friends, family, schoolmates or colleagues; (14) I often follow about what is going on in the election. The items for each scale are loosely based on study by Gibson, Lusoli, and Ward (2005).

To assess the level of political efficacy of the respondents, I used the combination from several recent elections studies conducted in the United States, for example, found that political efficacy is a key determinant of political participation (Bromley, Curtice, 
\& Seyd, 2004; Kaid, McKinney, \& Tedesco, 2000; Livingstone \& Markham, 2008):

I am better informed about politics and government than most people; (2) I have a good understanding of the election system and process; (3) I am aware of the important political campaign issues in this election; (4) I know the background of the contesting candidates in my constituency; and (5) My vote in the 2014 general election will make a difference.

With the assumption that news exposure of election might be associated with political participation, I adapt several items from Willnat, Wong, Tamam \& Annette (2013) to measures the use of online news media. This part consist of five items: (1) I read news through online news media is part of my everyday activity; (2) I feel out of touch when I have not accessed onto news website for a while; (3) I often follow the news about the 2014 election through online news media; (4) I often go online to get election news every week; (5) I access political news through online media every day.

In order to do the hypotheses testing, the author used correlation analysis. The purpose of doing correlations is to make a prediction about the relationship of one variable to another. Positive correlation means that high scores on one are associated with high scores on the other, and that low scores on one are associated with low scores on the other. Negative correlation, on the other hand, means that high scores on the first thing are associated with low scores on the second. Negative correlation also means that low scores on the first are associated with high scores on the second.

\section{Results and Discussion}

The findings and result of the respondents can be seen from Table 1. It is the evident that the majority of the respondents were female. More than half of total respondents of these Indonesian students in Taiwan were in the age group of $22-26$ years old, $60.68 \%$ of the sample population. The survey also found that more than half were students who study in master degree. It is important to note and reasonable that most of Indonesian students who study in Taiwan are master students. Their ages are approximately within 22 to 26 years old.

In addition, this study also found that about three fourths $(78.64 \%)$ of respondents surfed the Internet more than two hours per day. Among these users, about $12.14 \%$ reported they were online for 60-120 minutes daily. Regarding specific online news media usage, more than one third $(35.44 \%)$ of the respondents read online news at least 30 minutes per day. 
Table 1. Demographic of respondents

\begin{tabular}{cccc}
\hline Profile & Description & Respondent & Percentage (\%) \\
\hline Age & $17-21$ & 26 & $12.62 \%$ \\
& $22-26$ & 125 & $60.68 \%$ \\
& $27-31$ & 41 & $19.90 \%$ \\
& $32-36$ & 10 & $4.85 \%$ \\
Gender & over 36 & 4 & $1.94 \%$ \\
\hline Education & Male & 98 & $47.57 \%$ \\
& High school or & 108 & $52.43 \%$ \\
\hline & lower & 6 & $2.91 \%$ \\
& Bachelor degree & 65 & $31.55 \%$ \\
& Master degree & 112 & $54.37 \%$ \\
Internet time & Doctoral degree & 23 & $11.17 \%$ \\
\hline spend & $1-15$ minutes & 3 & $1.46 \%$ \\
& $16-29$ minutes & 2 & $0.97 \%$ \\
& $30-59$ minutes & 14 & $6.80 \%$ \\
& $60-120$ minutes & 25 & $12.14 \%$ \\
& more than 2 hours & 162 & $78.64 \%$ \\
\hline Online news & $1-15$ minutes & 30 & $14.56 \%$ \\
time spend & $16-29$ minutes & 28 & $13.59 \%$ \\
& $30-59$ minutes & 73 & $35.44 \%$ \\
& $60-120$ minutes & 38 & $18.45 \%$ \\
& more than 2 hours & 37 & $17.96 \%$ \\
\hline & & &
\end{tabular}

As can be seen on table 2 online news media usage has a significant contribution to online political participation $(\mathrm{Sig} .=0.000)$. However, Pearson Correlation is 0.296 which indicates the relationship between variable is not strong $(0<0.3=$ weak $)$.

As expected, the data and analysis indicated that online news media usage have positive relationship with online political participation. Respondents who consumed or used online news media were more likely to engage in politics online. The more people consume news through online media, the more people participate in politics.
Clear examples of the exposure of online news media associated with political participation online is the study found by Tolbert and McNeal (2003). The findings showed that the use of online news was significantly associated with voting in the 1996 and 2000 U.S. presidential elections. Examining data from the 2000 National Annenberg Election Survey, Kenski and Stroud (2006), on the other hand, found small but significant associations between Internet use and political knowledge, efficacy, and participation. Furthermore, Di Gennaro and Dutton's (2006) study of Internet data in the United Kingdom also found that 
Table 2. Bivariate Correlations Among Online News Media Usage, Online Political Participation, and Political Efficacy

\begin{tabular}{lccc}
\hline Subscale & 1 & 2 & 3 \\
\hline 1. Online News Media Usage & -- & $.296^{* *}$ & $.736^{* *}$ \\
2. Online Political Participation & & -- & $.378^{* *}$ \\
3. Political Efficacy & & -- \\
\hline **. Correlation is significant at the 0.01 level (2-tailed). & &
\end{tabular}

online use had a significant impact on political interest, efficacy, and online participation.

Internet facilitates political information access for Indonesian citizens who live in Taiwan. Online news became the only reliable tool to catch up with the information related with politics rather than traditional media. Thus, it is safe to conclude that the use of online news media correlated positively with online political participation for Indonesian students in Taiwan during the 2014 election.

There was also a significant correlation between online news media usage and political efficacy $($ Sig. $=0.000)$. The relationship within these two variables is strong (Pearson Correlation $=0.736)$.

As expected, respondents who access online news media indeed are more likely to have better understanding about politics. For example, Kenski and Stroud (2006) stated that Internet access and exposure to online information about the 2004 U.S. presidential campaign were significantly associated with political efficacy and knowledge. Furthermore, it is obvious that interactivity of respondents, by discussing topic related with politics, can enhance their political knowledge. As a summary, I can say that the students who use Inter- net, especially accessing online news exhibit higher of political knowledge than the others who do not use the Internet for such activities. Thus, online news media consumption was significantly correlated with political efficacy.

I assumed that political participation will exhibit higher level of political efficacy. Result in table 2 shows, that there was a significant correlation between online political participation with political efficacy (Sig. = 0.000). The relationship within these two variables is relatively weak (Pearson Correlation $=0.378)$.

Political participation is important because levels of engagement in a democratic system have consequences on the system's equity. Thus, Internet exposure boosts the online political participation and increases political efficacy and knowledge. The Internet also gives individuals easy access to information about politics as many Web sites are designed with the objective of informing citizens about candidates, issues, and politics in general.

Even though the relationship between these two variables is relatively weak, it is safe to conclude that online political participation correlated positively with political knowledge and exhibit higher level of political efficacy 
for Indonesian students in Taiwan during the 2014 election.

This study provides several interesting result about Indonesian students online political participation toward elections in Indonesia. In overall, in its field, this research presents the first systematic empirical study upon the online political participation of Indonesian students in Taiwan. As Di Maggio et al. (2001) and Xenos and Moy (2007) pointed out in their studies, as long as the technology continues to change, the political life will also change in time. They argued that both of technology and political participation have correlation and influence one to another. Thus, the results of this study have a history than scientific value and the relationship within the studied variables will presumably evolve.

This study explored the potential relationship between online media use and political participation of Indonesian students in Taiwan, which is unique because most of prior research analyzed the situation happened in Western societies and most of the research are conducted inside the country not outside the country. Indonesian 2014 general election presented an ideal opportunity to test how online media play role in political event. By the lack of information exposure from television and newspaper, Indonesian people who live in Taiwan more likely use online media in order to get information.

Overall, the findings show that online news media usage was positively associated with higher political participation and efficacy among Indonesian students during the
2014 general election. This interpretation is strengthened by the fact that online news media usage has a significant contribution to online political participation $($ Sig. $=0.000)$. The relationship between the variables is positive, however, the strength of relationship is weak (Pearson correlation is 0.296 ; the value between 0 to 0.3 is weak).

On the other hand, online news media usage also had positive correlation with political efficacy. It can be seen on table 2, that there was a significant correlation between online news media usage with political efficacy $($ Sig. $=0.000)$. These two variables indicated positive relationship and the strength of the relationship is strong (Pearson Correlation = 0.736 ; the value over 0.5 is strong).

As expected, respondents who access online news media indeed are more likely to have better understanding about politics. The finding confirmed previous study from Kenski and Stroud (2006) which is noted that online media use and political participation have significant associations.

Although the findings showed that there was a positive relationship within online media use, political participation and political efficacy, there is still a need for basic political motivation for the individuals to use the Internet for political purposes. The results display that the students were looking for political information and keep following the political situation in Indonesia through online media. But however, they did not do further action like visiting the website of political party or candidates, sign up for volunteer to help polit- 
ical cause, joining a political organization online as a member and sign for online petition. Here, it can be said that although the Internet may not increase the political interest or passive participation, it enables the users to show their direct participation in politics. In brief, the internet provides a venue for political activity which can be considered as an extension of the actual political life. In short, political participation was associated with all variables in this study, possibly because most of Indonesian students in Taiwan in this research planned to vote anyway.

With the results and findings above, however, it still safe to conclude that the Internet served as an alternative medium that not only provided more diverse political information about the 2014 election in Indonesia, but also gave voters an unprecedented chance to directly engage in political process. Online media, specifically news, played a key role in promoting political participation for Indonesian community who live across the countries.

Like many similar researches, this study is not immune from limitation, either, and there is still a need for further researches to be performed in this field. Although it is important to note the contextual setting in which this study observed, this study also need to acknowledge that the study and results did not focus on daily political interests, motivation and the relative political participation of Indonesian students in Taiwan. It would be interesting to see the online and offline political activity of the students during political elections time or during an extraordinary political environment such as voting.

Another drawback is that the data for this study was gathered from Indonesian students who are mainly from Taiwan. The result also cannot generalize to overseas Indonesian population. Therefore it would be more fruitful to observe the online political participation of Indonesian students from several countries in each different region such as America, European countries and other Asian countries.

Lastly, political and /or ideological preferences of the students have not been taken into account in this research. This aspect of the matter could provide another valuable variable which would help to define the type and the magnitude of the online political participation.

\section{References}

Anduiza, E. et al. 2009. "Political participation and the Internet." Information, Communication and Society 12(6): 860-878.

Conway, M. Margaret (2000). Political Participation in United State, Third Edition. Washington, D.C., Congressional Quarterly Inc.

Dahlgren, Peter. (2009). Media and political engagement: citizen, communication and democracy. New York. Cambridge University Press.

Di Gennaro, C., \& Dutton, W. (2006). The Internet and the public: Online and offline political participation in the United Kingdom. Parliamentary Affairs, 59(2), 299-313.

Kenski, K., \& Stroud, N. J. (2006). Connections between Internet use and political efficacy, knowledge, and par- 
ticipation. Journal of Broadcasting \& Electronic Media, 50(2), 173-192.

McQuail, D. (2010). McQuail's mass communication theory. Sage Publications.

Morris, M., \& Ogan, C. (1996). The Internet as mass medium. Journal of Communications, 46(1), 39-50.

Nie, Norman H., Sidney Verba and Jae-on Kim. 1976. "Political Participation and the Life Cycle." Comparative Politics 6: $319-340$.

Nisbet, M. C., \& Scheufele, D. A. (2004). Political talk as a catalyst for online citizenship. Journalism \& Mass Communication Quarterly, 81, 877-896.

Parry, G., Moyser, G., \& Day, Neil. 1992. Political Participation and Democracy in Britain. Cambridge: Cambridge University Press. Pp.145-151.

Rice, Ronald E. (2002). Primary Issues in Internet Use: Access, Civic and Community Involvement, and Social Interaction. In Lievrouw, Leah A. \& Livingstone, Sonia (Eds.), Handbook of New Media. (pp. 105-130). London, Sage Publication Ltd.

Soebagio, H. IMPLIKASI GOLONGAN PUTIH DALAM PERSPEKTIF PEMBANGUNAN DEMOKRASI DI INDONESIA. Sumber, 21, 8.

Suryanef, S. (2011). Persepsi Politik Mahasiswa FIS Universitas Negeri Padang. Jurnal Demokrasi, 10(2).

Willnat, L., Wong, W. J., Tamam, E., \& Aw, A. (2013). Online Media and Political Participation: The Case of Malaysia. Mass Communication and Society, (just-accepted).

Wimmer, R. D., \& Dominick, J. R. (1994). Mass media research: An introduction. Belmont, CA: Wadsworth.

Winneg, K. M. (2009). Online Political Participation In The 2008 US Presidential Election: Mobilizing Or Reinforcing?. Publicly accessible Penn
Dissertations, 72.

Wolfinger, Raymond E. and Rosenstone, Steven J. 1980. Who Votes? New Haven, CO: Yale University. 